\title{
Endemic methicillin-resistant Staphylococcus aureus: Nurses' risk perceptions and attitudes
}

\author{
Ana Luisa Pedro RN ${ }^{\mathrm{a}, *}$, António Sousa-Uva MD, $\mathrm{PhD}^{\mathrm{b}}$, Elaine Pina $\mathrm{MD}^{\mathrm{c}}$ \\ a Infection Control Committee, Centro Hospitalar de Lisboa Central, Lisboa, Portugal \\ ${ }^{\mathrm{b}}$ Occupational and Environmental Department, Escola Nacional de Saúde Pública, Lisboa, Portugal \\ ${ }^{c}$ Programa de Prevenção e Controlo de Infecção e Resistência aos Antimicrobianos, Direcção Geral de Saúde, Portugal
}

\section{Key Words}

Staphylococcus aureus

Methicillin-resistant Staphylococcus aureus

Risk perception

Behavior

Infection control
Dissemination of methicillin-resistant Staphylococcus aureus (MRSA) remains one of the most difficult challenges for prevention, control, and treatment of health care-associated infections. A survey and interviews were conducted on nurses from a hospital center. We found that most nurses' perceived risk of acquiring MRSA related to themselves (72\%), other nurses (88.5\%), and patients (97.8\%). This perception influences attitudes, leading to compliance with the existing recommendations.

Copyright $\odot 2014$ by the Association for Professionals in Infection Control and Epidemiology, Inc. Published by Elsevier Inc. All rights reserved.
In Portugal, methicillin-resistant Staphylococcus aureus (MRSA) is endemic in most hospitals, with resistance rates $>49 \%$ in cerebrospinal fluid and blood samples. ${ }^{1}$ Several international organizations have developed guidelines for prevention and control of MRSA, $^{2-4}$ namely patient isolation or cohorting, contact precautions, active patient screening at admission, decolonization, and environmental decontamination.

Full adoption of guidelines for prevention of cross infection depends on the awareness of the guidelines and risk perception related to the presence of MRSA by health care workers (HCWs). Behavioral theories suggest that a high-risk perception encourages individuals to adopt actions to reduce risk. ${ }^{5,6}$

\section{METHODS}

We conducted a cross-sectional study to determine perception and attitudes in relation with risk of exposure to MRSA. The study included nurses from 10 clinical units in a teaching medical center in Lisbon, which is composed of 4 hospital sites, though only 2 were used to conduct the study, in old buildings with wards of $\geq 4$ beds and very limited isolation facilities. Wards with patients with more risk factors for acquiring MRSA and where surveillance of MRSA has been in place longer were selected.

\footnotetext{
* Address correspondence to Ana Luisa Pedro, Rua de França $n^{\circ} 10-2^{\circ}$ Direito, 2605-222-Belas, Lisbon, Portugal.

E-mail address: analuisapedro@netcabo.pt (A.L. Pedro).

Conflict of interest: None to report.
}

We intended to identify nurses' knowledge about the MRSA chain of transmission and nurses' perception of risks related to acquisition and transmission of MRSA for themselves, other nurses, and patients. We also identified how knowledge and perception are reflected in practices described by HCWs.

The study protocol was submitted for approval by the hospital board and ethics committee. Internal consistency was evaluated with the Kaiser-Meyer-Olkin test. ${ }^{7}$ After factorial analysis the sentence about "MRSA isolation report in discharge and transfer forms" was categorized as "risk perception" for purposes of analysis. Following expert review, the questionnaire and semistructured interview guide were subjected to pilot testing on a sample of the study population and were modified accordingly.

The self-assessed anonymous questionnaire was distributed to a sample of nurses from 3 intensive care units and 7 medical wards (MWs). Additionally, an interview was conducted with 1 nurse per unit, selected on a voluntary basis.

The questionnaire was composed of 21 items: 6 assessed knowledge, 8 addressed risk perception, and 7 addressed attitudes. Knowledge questions were multiple choice, and risk perception and attitudes were rated with a 5-point Likert-type scale. In the interviews, a visual analog scale was used to evaluate risk perception. In general, the statements were designed to elicit an agreement as the correct answer, with exception of statements related to time spent on the tasks.

As appropriate, the $\chi^{2}$ (qualitative variables) and MannWhitney $U$ or Wilcoxon tests (quantitative variables) were applied. A $P$ value $<.05$ was considered statistically significant. The Bardin method was used for analysis of interview content. ${ }^{8}$ 


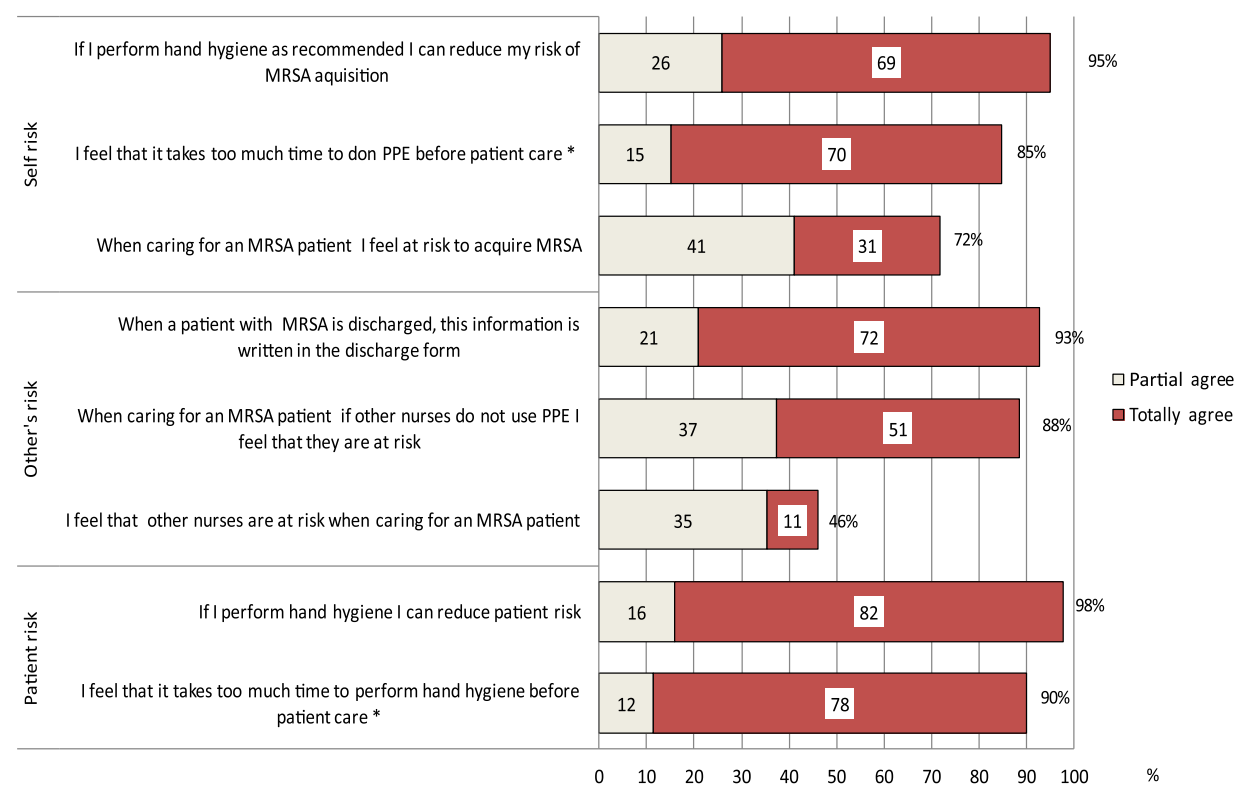

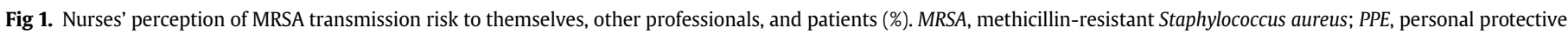
equipment. *Answer considered: totally disagree versus disagree.

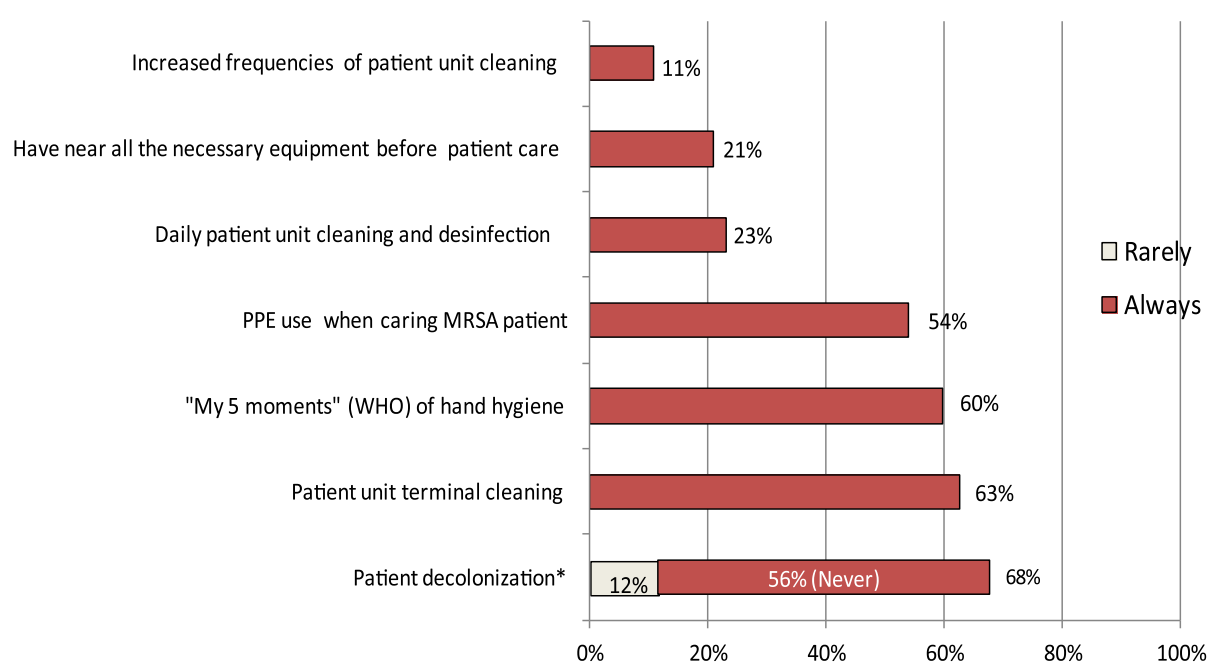

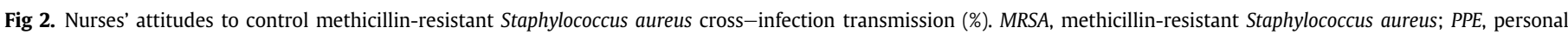
protective equipment; $W H O$, World Health Organization. *Answer considered: rarely versus never.

\section{RESULTS}

After excluding the pretested and interviewees, 212 questionnaires were distributed, and 139 (65.6\%) valid responses were received. The respondents were predominantly women $(84.9 \%)$, with mean professional experience of 8.8 years (range, 0 -34 years). Most worked in MWs ( $\mathrm{n}=90 ; 64.7 \%)$.

\section{KNOWLEDGE}

A mean of 3 correct answers was obtained for the 6 knowledge questions. The most frequently correct answers were related to sources of MRSA (77.7\%), professionals' colonization risk (64\%), professionals' hands as a major route of transmission (64\%), and microbiologic characterization of MRSA (58.3\%). The less frequently correct answers were those referring to risk factors and $S$ aureus resistance rates in Portugal (46\% and $18 \%$, respectively).

\section{RISK PERCEPTION}

In general, $71.9 \%(\mathrm{n}=100)$ nurses agreed that they can be at risk to acquire MRSA (Fig 1). Adopting preventive measures, such as hand hygiene (95\%) and donning personal protective equipment (PPE) (84.9\%), were seen as reducing personal risk. Professionals who felt at risk $(n=100)$ agreed that other nurses were also at risk ( $\mathrm{n}=95$; odds ratio $[\mathrm{OR}]=7.49 ; 95 \%$ confidence interval $[\mathrm{CI}]$, 
2.13-29.27; $P<.001)$; 88.5\% felt that when other nurses did not wear PPE, their risk increased. An increased risk for the patient was perceived by $97 \%$ of nurses. Of the nurses, $71.9 \%(n=100)$ always reported isolation of MRSA in discharge and transfer forms in writing.

\section{ATTITUDES}

Globally, 54\% ( $n=75$ ) of nurses answered always to PPE use and $59.7 \%(n=83)$ to hand hygiene. There was a strong correlation between those who responded positively to donning PPE and those who performed hand hygiene before patient contact (76\%; $\mathrm{OR}=4.63 ; 95 \% \mathrm{CI}, 2.12-10.25 ; P<.001)$.

MRSA patient isolation practices differed between clinical wards. Globally, respondents referred acting in conformity with the existing MRSA recommendations (Fig 2). In intensive care units, daily disinfection of the patient's unit was performed more frequently than in MWs ( $\mathrm{OR}=6.0 ; 95 \% \mathrm{CI}, 2.32-17.32 ; P=.001$ ). Terminal disinfection of the patient's unit after discharge was confirmed by $62.6 \%(n=87)$ of nurses.

Decolonization was an infrequent practice. Colonization risk for professionals was pointed out by 89 nurses; of these, 52 (58.4\%) always performed hand hygiene, and 44 (49.4\%) always donned PPE when caring for patients with MRSA. For 136 nurses (98\%), professionals' hand hygiene was the most important measure to reduce patient risk.

\section{INTERVIEWS}

Eight interviews were conducted. Through the use of the visual analog scale, no difference was observed in the median between perception of personal risk and risk to other nurses. Patient risk was felt to be higher than personal risk (Wilcoxon, $P<.05$ ). The potential patient risk was linked to professionals' lack of compliance with infection control guidelines.

The possibility of being colonized with MRSA was not a regular concern in daily practice. The use of PPE was referred by the interviewees as a widespread practice in clinical care.

Most of the respondents complied with standard and contact precautions. Interviewees confirmed patient dedicated equipment (7 of 8 participants), namely basins, thermometer, and sphygmomanometer cuff. Architectural conditions were referred as a limitation for adequate contact isolation. In the interviews, it was stated that reference to MRSA isolates in discharge and transfer forms depended on individual assessment. The need to improve communication among health care teams about infection prevention recommendations was stressed.

\section{DISCUSSION AND CONCLUSIONS}

Our findings show that nurses demonstrated only a reasonable level of knowledge (54.7\%). Questions related to MRSA national rate (18\%) and risk factors for acquisition (46\%) obtained less correct answers as was also observed by Easton et al. ${ }^{9}$
The perceived risk was influenced by the use of protective and containment measures. Existing prevention measures increased individual situation control perception and reduced risk perception as described by Brewer et al. ${ }^{10}$ Patient intrinsic risk factors were identified, and patient risk was well perceived by most of the respondents and interviewees.

In general, nurses complied with existing guidelines and performed contact precautions. Patient unit and equipment cleaning and discharge information of the MRSA isolates were the less implemented practices. Attitudes seemed to be influenced by risk perception. Professional behavior was linked with poor outcome in preventing cross transmission. Patient risk was perceived to be minimized if protective measures were performed.

The respondents that did not correctly answer the knowledge questions also complied with the guidelines. Influence of the behavior of professional role models and leaders seemed to have importance in the transmission of routine practices as pointed by Ajzen $^{5}$ and Bandura. ${ }^{6}$

Infection control professionals need to identify barriers to guideline implementation and find strategies based on behavioral theories to improve staff adherence to guidelines. ${ }^{11,12}$

These results justify future studies, such as observation of contact precaution practices, in-depth evaluation of knowledge in different types of HCW, and dissemination of information on MRSA rates and infection control institutional guidelines for prevention of multidrug-resistant organisms.

\section{References}

1. European Centre for Disease Prevention and Control. Antimicrobial resistance surveillance in Europe 2009. Annual report of the European Antimicrobial Resistance Surveillance Network (EARS-Net). Stocholm: ECDC. Available from: http://www.ecdc.europa.eu/en/publications/_layouts/forms/Publication_Disp Form.aspx?List =4f55ad51-4aed-4d32-b960-af70113dbb90\&ID=320; 2010. Accessed May 31, 2011.

2. Aureden K, Arias K, Burns LA, Creen C, Hickok J, Moody J, et al. Guide to the elimination of methicillin-resistant Staphylococcus aureus (MRSA) transmission in hospital settings. Association for Professionals in Infection Control and Epidemiology, 2nd ed. Washington, DC: ROCHE; 2010.

3. Coia JE, Duckworth GJ, Edwards DI, Farrington M, Fry C, Humphreys H, et al. Guidelines for the control and prevention of methicillin-resistant Staphylococcus aureus (MRSA) in healthcare facilities. J Hosp Infect 2006;63(Suppl 1): S1-44.

4. Siegel JD, Rhinehart E, Jackson M, Chiarello RN, The Healthcare Infection Control Practices Advisory Committee. Management of multidrug-resistant organisms in healthcare settings. Atlanta [GA]: CDC/HICPAC; 2006.

5. Ajzen I. The theory of planned behavior. Organ Behav Hum Decis Process 1991; 50:179-211.

6. Bandura A. Social cognitive theory of self-regulation. Organ Behav Hum Decis Process 1991;50:284-7.

7. Tabachnick BG, Fidell LS. Using multivariate statistics. Boston [MA]: Pearson Education Inc; 2007. p. 980.

8. Bardin L. Análise de conteúdo. Edições 70. 1977. [in Portuguese]

9. Easton PM, Sarma A, Williams FL, Marwick CA, Phillips G, Nathwani D. Infection control and management of MRSA: assessing the knowledge of staff in an acute hospital setting. J Hosp Infect 2007;66:29-33.

10. Brewer NT, Weinstein ND, Cuite CL, Herrington JE. Risk perceptions and their relation to risk behavior. Ann Behav Med 2004;27:125-30.

11. Pittet D. The Lowbury lecture: behaviour in infection control. J Hosp Infect 2004;58:1-13.

12. Cabana MD, Rand CS, Powe NR, Wu AW, Wilson MH, Abboud PA, et al. Why don't physicians follow clinical practice guidelines? A framework for improvement. JAMA 1999;282:1458-65. 